\title{
Commentary: Different routes, same destination?
}

\author{
Suk Jung Choo, MD, PhD
}

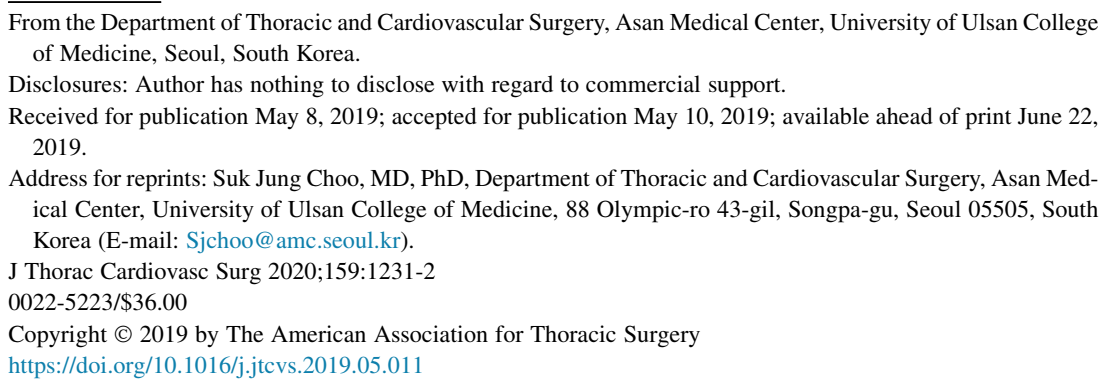

Left subclavian artery (LSA) revascularization may minimize the morbidity risks associated with LSA occlusion during zone 2 thoracic endovascular aortic repair (TEVAR), namely, ipsilateral arm ischemia and neurologic complications such as posterior stroke and spinal cord ischemia. ${ }^{1-3} \mathrm{In}$ this issue of the Journal, Bianco and colleagues ${ }^{4}$ reviewed their more than 10-year experience with LSA to left common carotid artery (LCCA) transposition during zone 2 TEVAR. The current level of evidence, however, does not favor one technique over another (ie, bypass versus transposition). Thus, the question that remains at this point regarding the proverbial "fork in the road" is...which route? Although the obligate need for deeper proximal dissection with LSA to LCCA transposition may seem technically more challenging, LSA bypass grafting also has its shortcomings, such as the need to use a vascular graft, which in the case of a small-diameter conduit may be associated with a greater risk of premature failure. ${ }^{5,6}$ Graft infection may be a potentially fatal complication in the event of the main stent graft involvement. ${ }^{7}$ LSA backflow-induced type II endoleak may also occur with bypass grafting, and although treatable, it may require additional interventional procedures. $^{8}$

What then are the pro arguments for LSA transposition? Use of only autologous vessels should lead to superior patency and a lower infection risk. On the other hand, any accident during the surgical exposure of the proximal LSA may be catastrophic. One such harrowing experience may be enough to dissuade any surgeon from choosing this approach. The risk of chylothorax may also be greater. However, Bianco and colleagues ${ }^{4}$ reported no catastrophic bleedings, only 1 case of chylothorax, and 1 case of posterior stroke. The 30 -day mortality rate was $5.17 \%$, but these deaths did not appear to be specific to the transposition procedure, and there was no intraoperative death. The authors otherwise report a $100 \%$ long-term patency rate with no phrenic nerve injury or infectious complications, and a 5 -year survival rate of $91 \%$. Despite these respectable

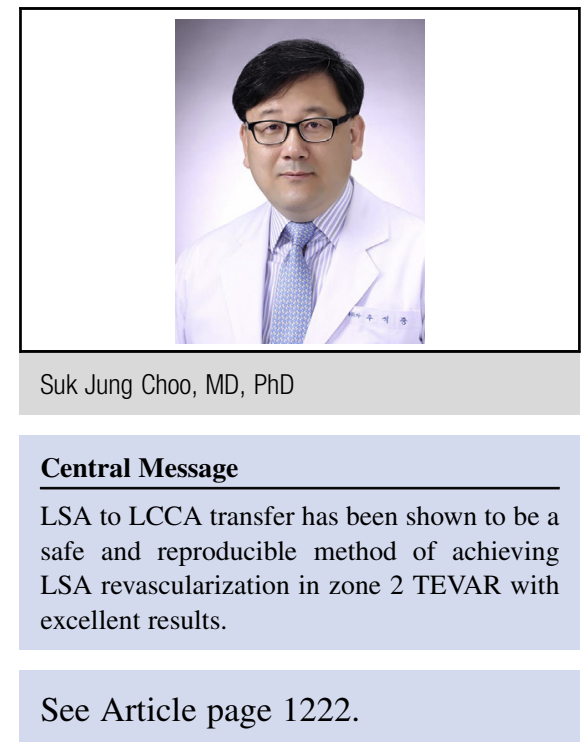

outcomes, there is no directly comparable LSA bypass counter group. In a recent report involving 112 patients undergoing LSA to LCCA bypass during TEVAR, Voigt and colleagues $^{9}$ noted phrenic nerve palsy in 27 patients $(25 \%)$ and a 30 -day mortality rate of $6 \%(n=5)$. The actuarial 5-year graft patency rate was $97 \%$ with a $3 \%(n=3 /$ 92) graft occlusion rate, among which 1 patient eventually required revascularization for subclavian steal syndrome. Although there were no reported cases of graft infections, the authors nevertheless deemed that the overall bypassrelated complications were not insignificant. In yet another larger prospective database review comparing LSA bypass with transposition, Madenci and colleagues, ${ }^{10}$ however, found no overall statistically significant differences in the infection, stroke, and death rates according to the surgical technique. Bearing these studies in mind, Bianco and colleagues ${ }^{4}$ demonstrated that LSA to LCCA transposition can be performed in a safe and reproducible manner with excellent outcomes, but the fact still remains that it is the actual revascularization of the LSA that really matters most in zone 2 TEVAR. Therefore, surgeons can rest assured that as long as LSA revascularization is achieved, the route chosen may matter less.

\section{References}

1. Buth J, Harris PL, Hobo R, van Eps R, Cuypers P, Duijm L, et al. Neurologic complications associated with endovascular repair of thoracic aortic pathology: incidence and risk factors. A study from the European Collaborators on Stent/ Graft Techniques for Aortic Aneurysm Repair (EUROSTAR) registry. J Vasc Surg. 2007;46:1103-11. 
2. Patterson BO, Holt PJ, Nienaber C, Fairman RM, Heijmen RH, Thompson MM Management of the left subclavian artery and neurologic complications after thoracic endovascular aortic repair. J Vasc Surg. 2014;60:1491-7.e1.

3. Ullery BW, McGarvey M, Cheung AT, Fairman RM, Jackson BM, Woo EY, et al Vascular distribution of stroke and its relationship to perioperative mortality and neurologic outcome after thoracic endovascular aortic repair. J Vasc Surg. 2012; 56:1510-7.

4. Bianco V, Sultan I, Kilic A, Arand-Michel E, Cuddy RJ, Srivastava A, et al. Concomitant left subclavian artery revascularization with carotid-subclavian transposition during zone 2 thoracic endovascular aortic repair. J Thorac Cardiovasc Surg. 2020;159:1222-7.

5. Kannan RY, Salacinski HJ, Butler PE, Hamilton G, Seifalian AM. Current status of prosthetic bypass grafts: a review. J Biomed Mater Res B Appl Biomater. 2005; 74B:570-81.
6. Budd JS, Allen KE, Hartley G, Bell PR. The effect of preformed confluent endothelial cell monolayers on the patency and thrombogenicity of small caliber vascular grafts. Eur J Vasc Surg. 1991;5:397-405.

7. Costerton JW, Stewart PS, Greenberg EP. Bacterial biofilms: a common cause of persistent infections. Science. 1999;284:1318-22.

8. Ratnam LA, Walkden RM, Munneke GJ, Morgan RA, Belli AM. The Amplatzer vascular plug for large vessel occlusion in the endovascular management of aneurysms. Eur Radiol. 2008;18:2006-12.

9. Voigt SL, Bishawi M, Ranney D, Yerokun B, McCann RL, Hughes GC. Outcomes of carotid-subclavian bypass performed in the setting of thoracic endovascular aortic repair. J Vasc Surg. 2019;69:701-9.

10. Madenci AL, Ozaki CK, Belkin M, McPhee JT. Carotid-subclavian bypass and subclavian-carotid transposition in the thoracic endovascular aortic repair era. J Vasc Surg. 2013;57:1275-82.e2. 